\title{
Using Fractal analysis to compare the characteristic complexity of Nature and Architecture: re-
} examining the evidence.

Josephine Vaughan, Michael J Ostwald

\begin{abstract}
Over the last few decades Complexity Scientists have shown that many natural systems possess similar geometric patterns that are repeated over multiple scales of observation. Using Euclidean geometry it is impossible to measure these forms as the closer the observer approaches the natural feature with a measuring device, the longer the result becomes. In response to this situation fractal geometry was developed as a means for determining, over progressive scales, the characteristic visual complexity of natural systems and forms. More recently it has been demonstrated that fractal geometry can also be useful for measuring the visual complexity of the constructed environment. As a result of this, it became possible, in the late 1990s to compare the fractal dimensions of both natural and constructed forms and thereby investigate the extent to which buildings are a reflection of their natural setting. The most famous examples of this provided evidence that a formal connection could be traced between the city of Amasya in Turkey and the landforms of its natural setting and a similar augment has been made about Sea Ranch in California. With only minimal evidence, a range of conclusions were drawn from this early work about the connection and influence of a local ecology on local architecture. The present paper re-tests these previous results using a more refined, computational version of the fractal analysis method and in doing so begins to explore the further application of this method for comparing natural and architectural forms.
\end{abstract}

Keywords: regional architecture, traditional architecture, computational fractal analysis

\section{Introduction}

A common proposition that is repeated in arguments about regional and environmentally sustainable architecture is that traditional dwellings are a reflection, in some way, of their natural setting (Bechhoefer \& Bovill, 1994). The present paper sets out to reconsider evidence that a quantitative comparison can be made, using fractal analysis, between natural and synthetic forms; say between a building and its geographic setting.

In 1994, William Bechhoefer and Carl Bovill applied Mandelbrot's box-counting method of fractal analysis to indigenous buildings and natural land forms in Amasya, Turkey. They concluded that each of these features had similar fractal dimensions and thus, the topography must have either influenced the design of the buildings, or alternatively all of these features were shaped by larger environmental conditions. Bovill reproduced these same findings in 1996 and further suggested that one way of determining a successful regional building could be to assess whether its fractal dimensions were 
similar to those of the surrounding landscape or vegetation. As an example, Bovill proposes that the highly irregular coastline of Sea Ranch (California) was closely echoed in Moore, Lyndon, Turnbull and Whitaker's famous Sea Ranch Condominium. In this way, Bovill suggests that there is potentially mathematical evidence that this famous critical regionalist building is responding to its natural setting in much the same way that the landscape has been shaped by local environmental and climatic forces.

Bovill's (1996) proposition has fascinated a number of scholars and it has been repeated in arguments about environmentally sustainable and regional architecture (Makhzoumi \& Pungetti, 1999). If valid, it could deepen our understanding of one form of ecologically responsive architecture, by providing quantitative results to demonstrate a relationship between the forms (three dimensional shapes or geometry) of local ecology and local architecture. However, the data supporting the Amasya findings has only once been reviewed (Lorenz, 2003) and the claims surrounding the Sea Ranch Condominium have never been tested. Moreover, none of these examples have used precisely the same analytical method so comparisons are difficult to make.

The present paper commences with an overview of the history of the use of fractal geometry to analyse the characteristic complexity of both natural features (Section 1) and of the built environment (Section 2). This is followed (in Section 3) by a description of the box-counting analytical method and its computational variation which is used for the later comparison of fractal dimensions. In the next section a close review of the original arguments is undertaken concerning the validity of comparing natural and constructed systems using fractal dimensions (Section 4). In the penultimate section of the paper (Section 5) the computational fractal method is applied to both Amasya and Sea Ranch and a comparative analysis of the original results and the new results is undertaken. Finally the paper reviews the validity of the two cases and their use to support the proposition that good regional and traditional dwellings will have similar characteristic complexity to their natural settings.

The present study has several practical limitations that should be considered before progressing. First, the research is not about environmentally sustainable architecture, but rather about testing the evidence that has been used to support one claim about the environmental responsiveness of regionalist architecture. Past research has consistently demonstrated that there is not necessarily any environmental benefit to mimicking a natural form in a synthetic construct (Ostwald \& Wassell, 2002; Ostwald, 2009). There may be good reasons for suggesting that a building should reflect its setting, but it is impossible to generalise this condition to claim that buildings which do not reflect their contexts are less sustainable than buildings that do. A second observation is that, even if the evidence for the cases of Amasya and Sea Ranch is poor, this does not completely invalidate all arguments about the relationship between form and setting, but it would call into question any claims derived specifically from these cases. Finally, the present testing process is largely focussed on images that have been previously used to support Bovill's argument. It is possible that these images are not representative or that better or worse ones are available, but for consistency the originals are used as 
the primary basis for the present research and are only supplemented when no alternatives are available. If this occurs, it is noted in the text.

\section{Measuring Natural Systems}

Measuring the world

Since Euclid developed a model of regular geometric relationships around 300BC, scientists and mathematicians have tried to use this system to measure and quantify the world by determining the size and complexity of any natural object or feature in the landscape. However, it wasn't until the 1970's that advances in geometrical thinking demonstrated that traditional Euclidian measurements give a very poor representation of the complexity of the world.

Benoit Mandelbrot in Les Objects Fractals: Form Hasard et Dimension (1975) proposed an alternative to Euclidian geometry; fractal geometry. According to Voss (1988), “Mandelbrot’s fractal geometry provides both a description and a mathematical model for many of the seemingly complex forms and patterns in nature and the sciences” (p. 21). From Mandelbrot's work it has been shown that star systems, geological formations, clouds, plant ecosystems, mountain ranges, coastlines and other natural systems typically possess similar geometric forms that are repeated over multiple scales of observation. Using Euclidean geometry, it is impossible to measure, with any accuracy, any dimensions such as lengths of these non-linear forms. However, Fractal geometry, by iterating measurements over progressive scales, can be applied to determine the characteristic visual complexity of natural forms. Fractal geometry is ideal for exploring the complex, and seemingly random forms found in the natural world. It is a geometry which can be used to demonstrate that within many chaotic systems a deeper rhythm of similar patterns is measurable. Fractal geometry then "provides a quantifiable measure of the mixture of order and surprise in a rhythmic composition" (Bovill, 1996, p. 3).

\section{Measuring the fractal geometry of nature}

In his 1982 publication The Fractal Geometry of Nature, Mandelbrot continues to explain, develop and refine the applications of fractal geometry, further exploring the fractal qualities of nature. Mostly, the publication describes methods for producing visual images of nature's forms from algorithms; plotting mathematical "forgeries" of nature. However, of interest to scholars who seek to represent the complexities of nature in a clear and comparable manner, Mandelbrot provides an explanation of several methods used to calculate the dimensions of natural forms, using fractal geometry. He states that "[s]cientists will (I am sure) be surprised and delighted to find that not a few shapes they had to call grainy, hydralike, in between, pimply, pocky, ramified, seaweedy, strange, tangled, torturous, wiggly, wispy, wrinkled, and the like, can henceforth be approached in rigorous and vigorous quantitative fashion” (Mandelbrot, 1982, p. 5). Voss (1988) argues that fractal geometry is particularly "appropriate for natural shapes” (p. 26) and that at "large scales, natural boundaries, geological 
topography, acid rain, cloud, rain and ecosystem boundaries, seismic faults, and the clustering of galaxies are all susceptible to fractal analysis” (p. 36).

In The Fractal Geometry of Nature, Mandelbrot considers particular natural forms and systems which can be analysed and measured. Included are calculations for measuring lengths and irregularity of rivers, lakes, and trees as well as the fractal dimension of the sky, clouds and galaxies. In particular Mandelbrot considers the length of coastlines in some depth providing a famous explanation of fractals. Mandelbrot seems pleased that "coastline length turns out to be an elusive notion that slips between the fingers of one who wants to grasp it” (Mandelbrot, 1982, p. 25), that is, until he proved that a fractal dimension can be calculated for any coastline, and he demonstrated the usefulness of this dimension by calculating and comparing the coastlines of several nations.

Mandelbrot's work has been adopted by many others as a method for providing a quantitative understanding of the natural world. Lovejoy has analysed clouds, measuring their fractal dimension, which he describes as “'wiggliness' or degree of contortion of the perimeter” (1981, p. 196). Fractals have been utilised for large scale analysis including Peebles (1989) research on galaxy distribution. At a much finer level, Lung and Zhang (1989) are amongst many scholars who use fractal geometry to measure and attempt to predict the growth of cracks in physical surfaces. Using fractal geometry to measure vegetation growth or decline is now a common method in botanical studies. For example, Morse, Lawton, Dodson and Williamson (1985) calculate the fractal dimension of the outlines of certain plants and then consider how the insects living on them might be affected by the lower or higher fractal dimension of the plant. Others have added to the existing data of measured coastlines with calculations of Norway (Feder, 1988), Britain and California (Bovill, 1996). Makhzoumi and Pungetti propose fractal analysis as a method to interpret and understand the ecological landscape (1999). Recently, the fractal dimension of several Australian landscapes have been tested and the conclusion reached that "different landscape types can be calculated by their mean fractal dimension" (Perry, Reeves \& Sim, 2008, p. 15).

Fractal geometry has also been used to analyse preferences for the visual complexity of natural landscapes (Keller, Crownover \& Chen, 1987; Stamps, 2002; Hagerhall, Purcell \& Taylor, 2004). The method used in this research extracts silhouettes of natural landscape items and calculates the fractal dimension of the resulting linear forms. Keller, Crownover and Chen initiated much of the methodology in this area of study. Their work attempts to use fractal parameters to distinguish between different elements in a natural scene, such as a mountain and a tree. The process involves taking silhouettes from photographs at different scales of trees and mountains. The results found that "the $D$ values are relatively stable and the recovered values for tree lines are considerably higher than those for the smoother mountain line” (1987, p. 624). In other words, the fractal dimensions for trees fell into a similar grouping, while the dimensions for the mountains fell into another cluster. The authors were satisfied that fractal dimension ranges can be used to distinguish between different 
elements in nature. The ongoing work of Hagerhall, Purcell and Taylor (2004) is largely focused on determining preferences for images of certain fractal dimensions and they agree that an important procedural method is analysing the "silhouette outline between sky and landscape" (p. 248). They reason that the silhouette can be extracted without personal judgement by a software program and that past research by themselves and others has included silhouettes so the collection of data can be increased by continuing work in this area.

\section{Measuring Architecture}

Mandelbrot (1982) not only pioneered the application of fractal geometry to nature, he also suggests that it may be useful in understanding the properties of human creations, such as art and architecture. Mandelbrot says of fractal geometry that "[i]t describes many of the irregular and fragmented patterns around us" (1982, p. 1). In this way, buildings can be considered as "irregular and fragmented patterns”, as most built forms or urban layouts produce repeated shapes at different scales. According to Bovill,

[w]e experience architecture by observing the overall profile of a building from a distance; as we approach closer, the patterns of window and siding come into attention; as we approach even closer, the details of doors and window frames come into attention, down to what the door knob is like. The process then continues inside the building. The fractal characteristic of an architectural composition presents itself I this progression of interesting detail as one approaches, enters and uses a building (Bovill, 1996, p. 117).

This description is reminiscent of Mandelbrot's claim that "in the context of architecture: A Mies van der Rohe building is a scalebound throwback to Euclid, while a high period Beaux Arts building is rich in fractal aspects” (1982, p. 23-24). Just as Mandelbrot has used mathematical methods to calculate the fractal dimension of coastlines and compare them, so could architecture be analysed and compared for visual complexity (Bovill, 1996).

There are various traditions involving the fractal analysis of the built environment. At a macro-scale, the fractal analysis of urban plans has been occurring for almost 20 years. Kakei and Mizuno (1990) and Rodin and Rodina (2000) have applied fractal geometry to the analysis of historic street plans. At a larger scale Cartwright (1991) offered an overview of the importance of fractal geometry and complexity science in town planning and Batty and Longley (1994) and Hillier (1996) have developed increasingly refined methods for using fractal geometry to understand the visual and growth patterns of macro-scale urban environments. More recently, Batty (2005) has analysed the fractal dimension of various urban plans and Cardillo, Scellato, Latora and Porta (2006) have calculated the fractal dimension of the street patterns of 20 different cities. Ben Harmouche (2009) uses the concepts of fractal geometry to theoretically analyse and comprehend seemingly chaotic, traditional Muslim urban layouts. 
At a smaller scale, Bovill's 1996 work, Fractal Geometry in Architecture and Design, was the first major exploration of the relationship between fractal geometry and art, music, design and architecture. In particular, in this work Bovill demonstrates a mathematical way of measuring and comparing the fractal dimension of several important historical buildings. Bovill calculated the fractal dimension of these buildings using an application of Mandelbrot's box-counting technique, to determine the approximate fractal dimension, or characteristic visual complexity, of architectural plans and elevations. Bovill's box-counting method has since been employed to calculate the fractal dimension of a range of ancient buildings, including Mesoamerican pyramids (Burkle-Elizondo, 2001; BurkleElizondo \& Valdéz-Cepeda, 2006) and the fractal dimensions of the Doric, Corinthian and Composite orders of architecture (Capo, 2004). Sala reproduces Bovill's work on Frank Lloyd Wright's Robie house without any additional interpretation (2002) and Gozubuyuk, Cagdas and Ediz (2006) use the box-counting method to analyse the urban layout and typical buildings of two historical districts of the Turkish cities Istanbul and Mardin. Their purpose for the analysis was to use digital design methods to create a new building that might respond to existing architectural "languages" of the districts. Other scholars have suggested that the box-counting method could be used to determine if buildings with similar fractal dimensions to natural scenes will be aesthetically preferred by, and reduce the stress of, the general populace (Joye, 2007).

Although many scholars quote Bovill's work it remains, with the exception of Lorenz's (2003) extrapolation, almost completely untested. However, this paper is part of an ongoing process of thoroughly assessing Bovill's box-counting method and exploring its usefulness as an architectural application. In the last two years a computational variation of the fractal analysis method has been developed and tested by the present authors on the built works of Le Corbusier and Frank Lloyd Wright (Ostwald, Vaughan \& Tucker, 2008) partially confirming Bovill's original results. This computational method has since been used to analyse the domestic architecture of Eileen Gray (Ostwald \& Vaughan, 2008), Peter Eisenman (Ostwald \& Vaughan, 2009) and Kazuyo Sejima (Ostwald, Vaughan \& Chalup, 2009). This present paper records the first quantitative analysis of the application of the box-counting method, as a tool to compare nature and architecture, since the mid1990s (Bechhoefer \& Bovill, 1994; Bovill, 1996).

\section{The Box-Counting Method}

The method used to determine the fractal dimension of many of the aforementioned examples is known as "box-counting". This process can be applied to both two dimensional representations of architecture and to landscapes, vegetation and other natural forms. This method is thus useful for comparative measurements between architecture and its setting. The process of box-counting any natural or architectural object (figure 1) involves translating the subject into a linear image, such as the elevation of a building (figure 2) or the outline of a mountain. A grid is placed over this image and the number of squares which contain part of the image are noted (figure 3). This grid is then replaced by 
another with closer spacing, and the number of squares are counted once again (figure 4). This sequence progresses for a set number of iterations. The decreasing grid size allows for levels of detail in the image over different scales to be discovered. An object with a higher fractal dimension usually maintains highly detailed representation over many levels of observation. By plotting a comparison of the grid sizes with the number of counted boxes on a log-log graph, the slope of the resulting graph provides the fractal dimension, in the case of an image, a number between 1.0 and 2.0 (Bovill, 1996; Lorenz, 2003). The higher this number is (that is, the closer the number is to 2.0) the closer the image is to appearing as a two-dimensional object and thus the higher the visual complexity of the original object.
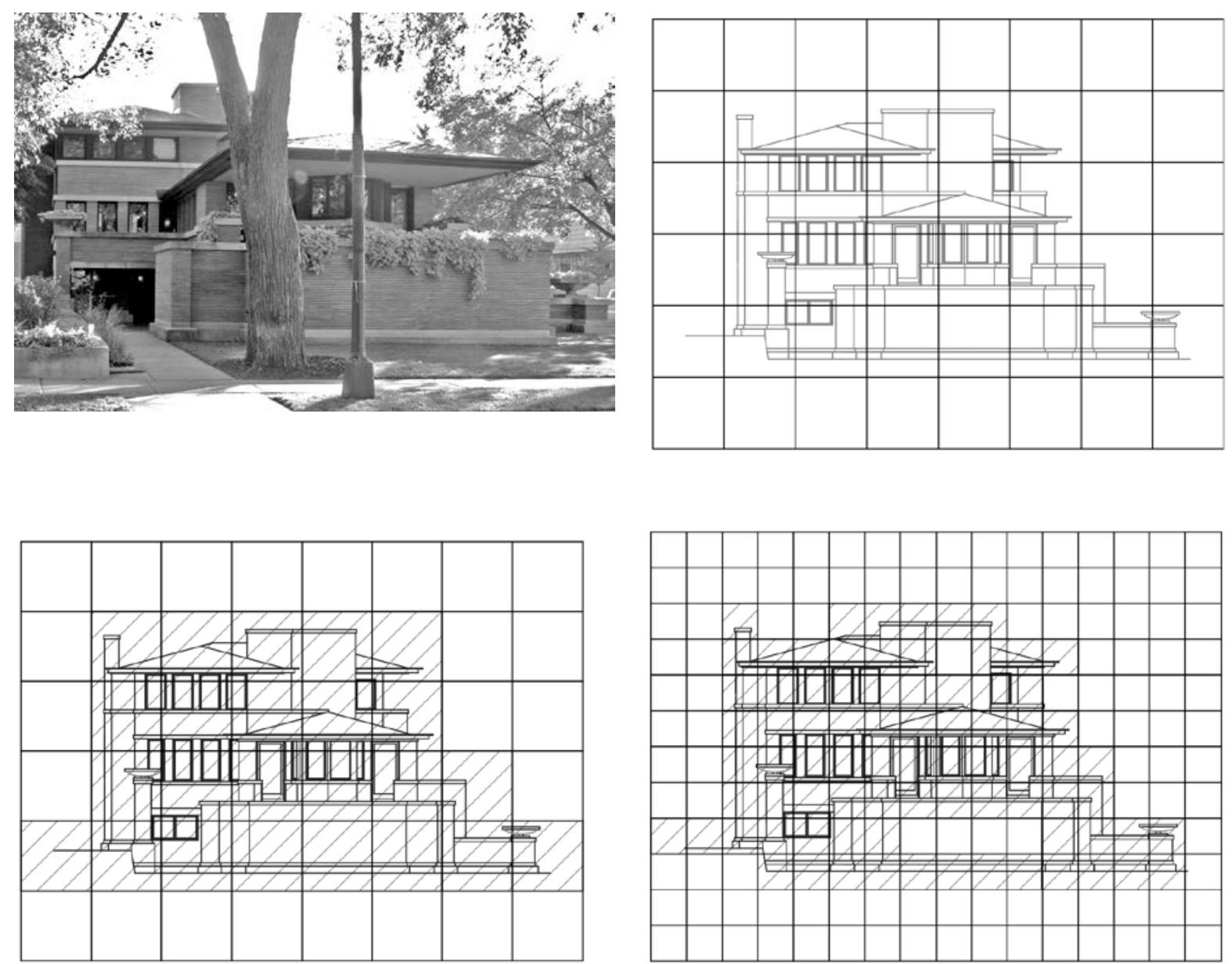

Figures 1-4. The Box-counting process.

The box-counting process has been automated and refined in computer programs such as Benoit (Trusoft's software for analysing the fractal dimension of images) and Archimage (a program developed by the University of Newcastle specifically to analyse the fractal dimension of architecture). The line image is loaded into the programs which then automatically select the positioning of the image in the grid, convert the original line work into single-pixel widths and count the detailed boxes over many iterations. The images analysed for this paper have been processed by 
both Benoit and Archimage, and the average result from both programs provides a final fractal dimension for the image. Utilising a computational variation allows for rapid analysis and a greater range of scales for analysis, however, deficiencies have been noted with the method including problems associated with line thickness, positioning of the original image and the significant lines selected for analysis (Ostwald, Vaughan \& Tucker, 2008; Vaughan \& Ostwald, 2009).

The resulting values of the fractal dimensions of images may then be compared to discover their numerical difference. The $D_{\text {(range) }}$ value provides the difference between the highest and lowest $D$ results of a selected set of images. The $\%_{\text {gap }}$ is the $D_{\text {(range) }}$ result expressed as a percentage of the possible maximum range (being $100 \%$ ) between $D=1.0$ and $D=2.0$ : thus $\%_{\text {gap }}=100 \times D_{\text {(range). }}$. Past research using this method has reported the \%gap data based on a range from $D=0.0$ to $D=2.0$ (ie. \% gap $\left.=\left\{100 \times D_{\text {(range) }}\right\} / 2\right)$ however, in the present paper, all reporting of \%gap results (old and new) has been corrected to the consistent range $D=1.0$ and $D=2.0$.

\section{Comparing Local Architecture and Local Ecology}

In conjunction with William Bechhoefer in 1994, Bovill published his first fractal dimension calculations on architecture. Bechhoefer and Bovill's paper utilises Mandelbrot's box-counting method of fractal analysis to undertake a comparative study which links the fractal dimensions of natural forms with the fractal dimensions of built forms. Working on the general assumption that there might be a visual "fit" between the local landscape and a building's appearance, Bechhoefer and Bovill applied fractal geometry to indigenous buildings and natural land forms in Amasya, Turkey. They concluded that the geology, topography and local environmental character had influenced the design of the buildings.

Bovill (1996) included the analysis of Amasya he undertook with Bechhofer in a later work, repeating their conclusion, that the natural conditions in some way influence the architectural design. In addition to the case of Amasya, Bovill also offers three additional examples where he believes a clear connection can be made between a natural setting and building. The first of this is between the design of Alvar Aalto's Home and Office and the tree spacing of the forest surrounding it. The second is between the highly irregular coastline and geology of Sea Ranch, California, and Moore, Lyndon, Turnbull and Whitaker's Sea Ranch Condominium complex. The final connection is proposed between the "relatively smooth" coastline at Nantucket and the "simple, basic shapes" of the houses there (Bovill, 1996, p. 181). To support these four cases, Bovill offers mathematical data concerning both the buildings and mountains in Amasya, and a calculation of the fractal dimensions of the coastline of Sea Ranch, but he does not analyse Sea Ranch Condominium. No data is presented for the analysis of Alto’s work nor the architecture or topography of Nantucket.

Accepting Bovill's arguments, Bechhoefer and Appleby (1998) propose that because "the fractal dimension of vernacular housing is very similar to that found in nature” (p. 3) then perhaps new 
buildings in historic settings should be designed to match similar levels of visual complexity and thus provide a better contextual fit. They then use fractal geometry, paradoxically aided by the musical patterns in a Brahms waltz, to generate the form and fenestration of a building design for the historical city of Aksehir in Turkey. This might seem a reasonable thing to do, to produce a new building which is sensitive to its historic setting, but there is much wrong with their proposal which borders on pastiche, and other researchers have rejected such simplistic responses (Ostwald, 2009). For example, Stamps (2002) questions the desirability of achieving a similar level of visual complexity for architecture and for its natural setting. As part of his extensive research investigating fractal dimensions of the built environment Stamps produced computer-generated images of mountains and cityscapes with deliberately matching fractal dimensions, and tested peoples' preferences for which should match. He concluded that his test subjects did not necessarily prefer the fractal dimension of the buildings to match the natural environment and that "urban design decisions regarding skylines should not assume that matching [fractal dimensions] of skylines and landscapes is a good idea" (Stamps, 2002, p. 170).

Nevertheless, interest in the relationship between buildings and landscapes continues in this field. In 2003, Lorenz reiterated Bovill's conclusions agreeing that "the measured fractal dimensions of the environment, elevation and detail will be similar” (p. 47). However, Lorenz' intention was to repeat Bovill's method, not to methodically test the veracity of his evidence. In essence, Lorenz confirms that Bovill's results are accurate, insofar as the original method and data allow. Further work connecting architecture and nature by way of fractal dimensions is even more limited in its presentation and use of quantitative data. Burkle-Elizondo and Valdéz-Cepeda, in their studies on the fractal dimensions of Mesoamerican pyramids, suggest that "it is possible to identify the pyramids with particular mountains in the landscape" (2006). Yet, although they provide calculations for the pyramids, they do not undertake calculations of the surrounding mountains to provide any evidence for their claims.

\section{Revisiting Amasya and Sea Ranch}

\section{Application of a comparative fractal methodology to Amasya}

The city of Amasya, Turkey, has been settled for over 2000 years. Members of the ruling royal family and important leaders were based there during the Ottoman period, when the city became established as a significant centre for creativity and the base for "many important court architects, artists, artisans and poets” (Bechhoefer, 1998, p. 25). The area of Amasya analysed by Bechhoefer and Bovill is Hatuniye Mahallesi which is "the historic neighbourhood on the north bank of the Yesilirmak River [and] is the clearest embodiment of Amasya's history. [...] The riverfront houses are among the most important assemblages of traditional residential construction in Anatolia” (Bechhoefer, 1998, p. 28). These buildings maintain much of their history and are set in a significant geographical location. Looming above the strip of old houses of Hatuniye Mahallesi is a large craggy hill, appearing as one 
massive peak. To compare the fractal dimensions of the architecture and the local landscape, Bechhoefer and Bovill undertook a box-counting analysis calculation on three images; a line drawing of the dominant hill (figure 5), the elevation of five connected historical houses along the river front (figure 6), and the urban layout plan of Hatuniye Mahallesi (figure 7). It is not clear where each of these images were sourced from or how the line drawings were produced.
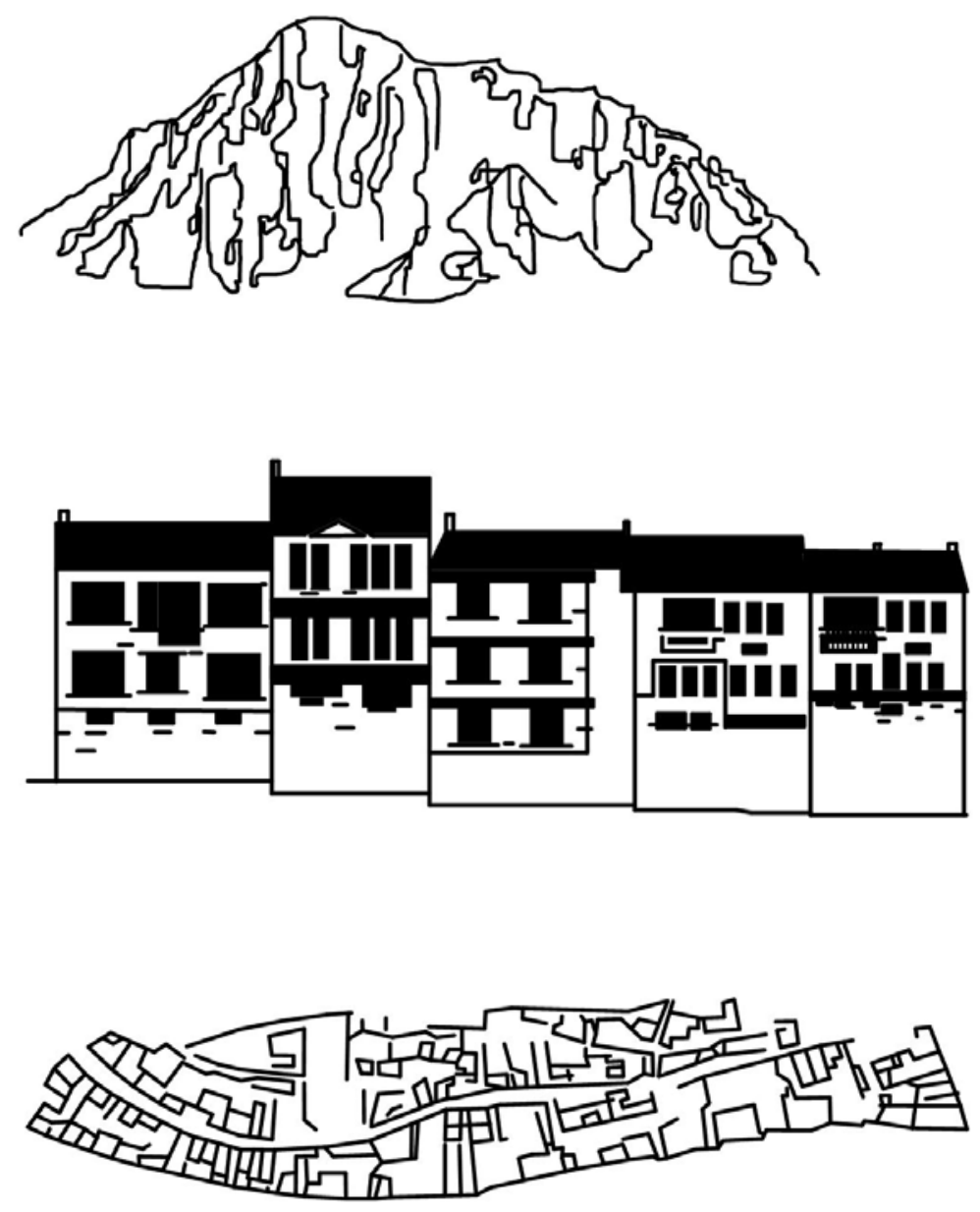

Figures 5-7: Reproduction of Bovill's images for fractal analysis of Amasya - the hill, the elevation of the row of houses and the urban plan

Bovill uses a manual method to produce a range of results for these three images (elevation, urban plan and hill) at Amasya and concludes that the "fractal dimension of the traditional housing is very close to that of the hill, which is the dominant visual feature of the city of Amasya. This suggests that the indigenous builders somehow applied the rhythms of nature to their housing site layout and elevation design" (1996, p. 145). In this context, what does "very close” mean?

Bovill's calculations for the fractal dimension, or $D$, of the three Amasya images range between a high of $D=1.717$ for the traditional house elevations to a low of $D=1.432$ for the urban plan. This is a 
range of $D=0.285$ which can be expressed as a percentage of the maximum possible range of $D$ for an image $(1.0<D<2.0)$. The gap represents a $28 \%$ range between the visual complexity of the three images as calculated by Bovill. Lorenz used an early version of the Benoit software to repeat Bovill's calculations in 2003. Lorenz's results recorded a high of $D=1.546$ (for the elevations) and a low of $D$ $=1.357$ (for the hill). The range was $D=0.189$ and the gap, expressed as a percentage, was $18.9 \%$. This seems to provide even stronger evidence for Bovill's conclusions. When the computational fractal analysis method (Ostwald, Vaughan \& Tucker, 2008) is applied to the three images the highest result is $D=1.585$ (for the urban plan) and the lowest is $D=1.495$ (for the hill). This is a gap of $D=$ 0.080 or $8 \%$ (see Table 1 ).

This analysis of two past data sets, and one new set, seems to suggest that the more accurate and consistent the method, the closer the three results are to supporting Bovill's conclusion. However, the recent analysis of sets of houses by Le Corbusier, Frank Lloyd Wright, Eileen Gray and Peter Eisenman has found that houses which appear to be genuinely visually similar will often have a gap of less than $2 \%$. Indeed, a gap of more than $8 \%$ suggests a significant difference in visual character.

Table 1: Comparison of fractal dimensions calculated for Amasya

\begin{tabular}{|l|l|l|l|l|l|}
\hline Results & $D_{\text {(elevations) }}$ & $D_{\text {(hill) }}$ & $D_{\text {(urban plan) }}$ & $D_{\text {(range) }}$ & $\%_{\text {gap }}$ \\
\hline Bovill (1996) & 1.717 & 1.566 & 1.432 & 0.285 & $28.5 \%$ \\
\hline Lorenz (2003) & 1.546 & 1.357 & 1.485 & 0.189 & $18.9 \%$ \\
\hline $\begin{array}{l}\text { This paper } \\
(2009)\end{array}$ & 1.505 & 1.495 & 1.585 & 0.080 & $8 \%$ \\
\hline
\end{tabular}

\section{Application of a comparative fractal methodology to Sea Ranch}

Bovill's second proposal, concerning the alignment between natural and built forms that are responsive to the environment, is focussed on Sea Ranch, California. This remote, exposed region north of San Francisco was developed in the 1960's into a township which set out to model regionalist and ecological principles of design, where the planning aim was "to link the character of natural form to the character of built form” (Halprin, 2002, p. 12). For this reason alone, the mathematical analysis of the relationship between the landscape and the buildings is of interest.

The highly irregular natural coastline and topography of Sea Ranch is described by Canty as "of wild beauty and intimidating power, more challenging than comforting: hillsides thick with fir and redwoods; grassy meadows mowed and mauled by sheep [...] cypress hedgerows [and] finally, the blue-green sea, surging against huge sculpted rock formations and steep bluffs, carving irregular 
inlets” (2004, p. 23). Bovill suggests this landscape is echoed in Moore, Lyndon, Turnbull and Whitaker's Condominium One, the first large building in the new Sea Ranch development. It is easy to understand Bovill's proposition because descriptions of the building regularly draw connections to the local context. For example, Lyndon and Alinder argue that the walls of Condominium One "drop like cliffs from its irregular edges, themselves further modulated by bays, projections, and hollows as they reach to the ground. The volume they make is like a large, rectilinear landform, a wooden escarpment with edges that move back and forth like the boundaries of a cove” (2004, p. 39).

Despite such clear conceptual links between the visual and formal qualities of Condominium One and the landscape of Sea Ranch, the only data provided by Bovill to support his argument are calculations of the fractal dimension of the coastline at Sea Ranch. In order to investigate any connection between the visual complexity of the landscape and of the building, new data has to be produced. For the present paper, the computational fractal analysis method has been used to recalculate the $D$ of the coastline image provided by Bovill (Figure 8). Then, for comparative purposes, the $D$ of the single image Bovill provides of Condominium One is also produced (figure 9). In addition, the coastline immediately beside Condominium One was redrawn from the site plan (Lyndon \& Alinder, 2004) (Figure 10) and finally, four new elevations of Condominium One were redrawn for the present paper based on original drawings by Moore and Turnbull (Johnson, 1986) (Figures 11 to 14), and an average fractal dimension calculated.
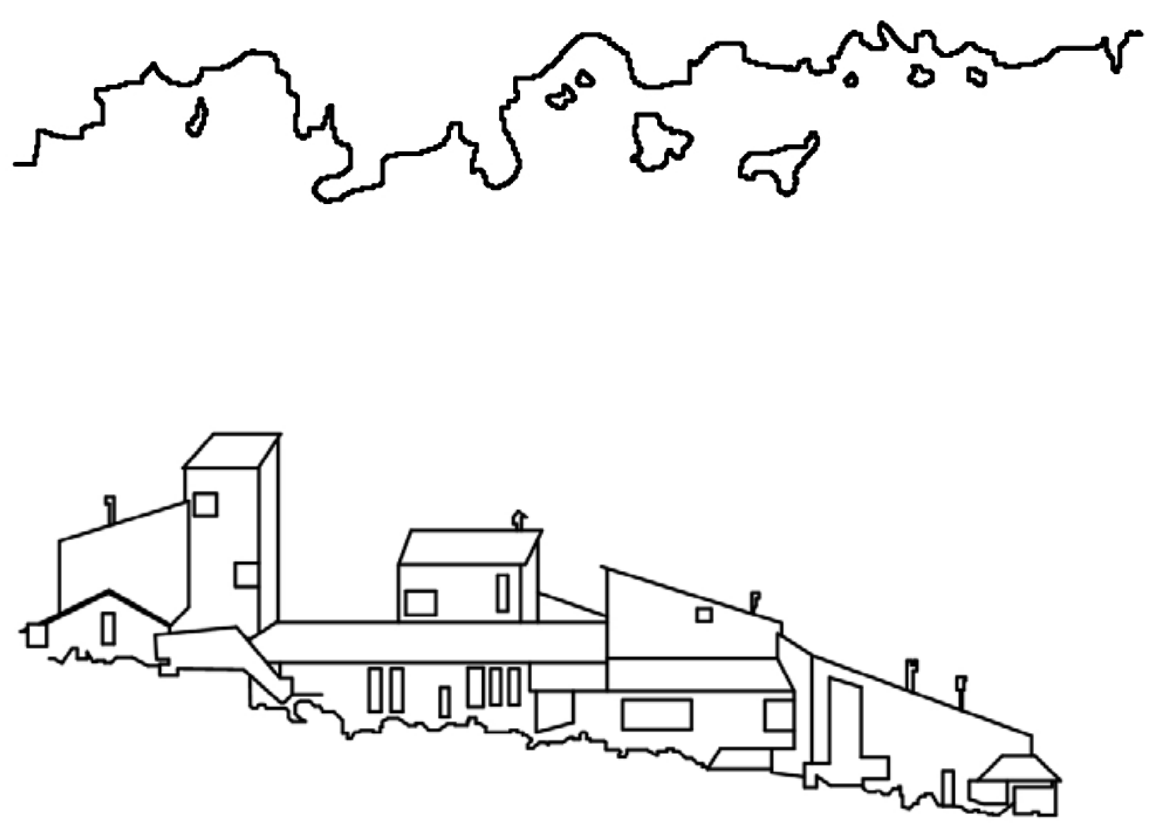

Figures 8 and 9. Reproduction of Bovill's images of the coastline $D=1.3215$ and Condominium One $D=1.426$ of Sea Ranch. 


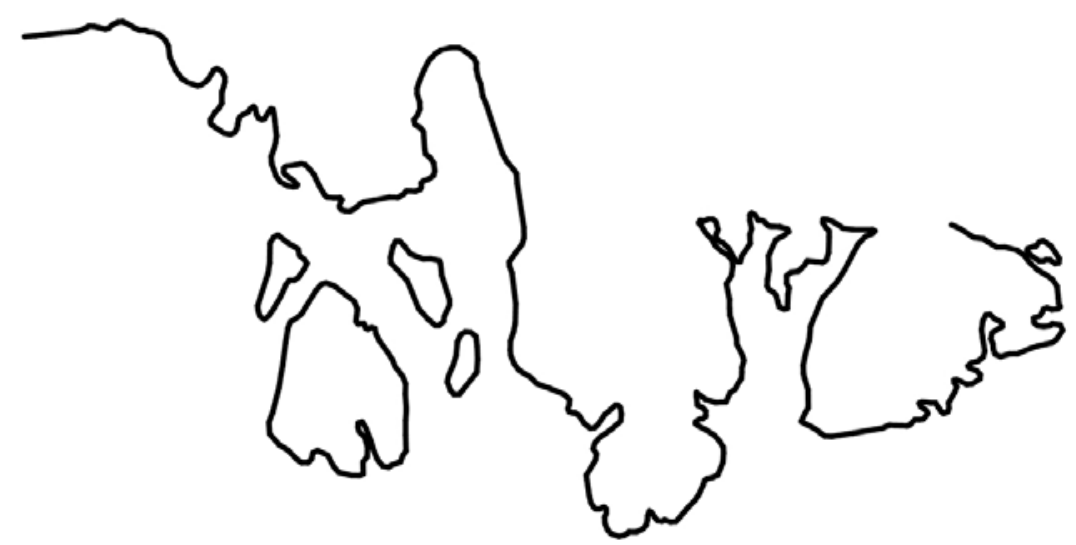

Figure 10 Reproduction of the coastline at Sea Ranch $D=1.249$
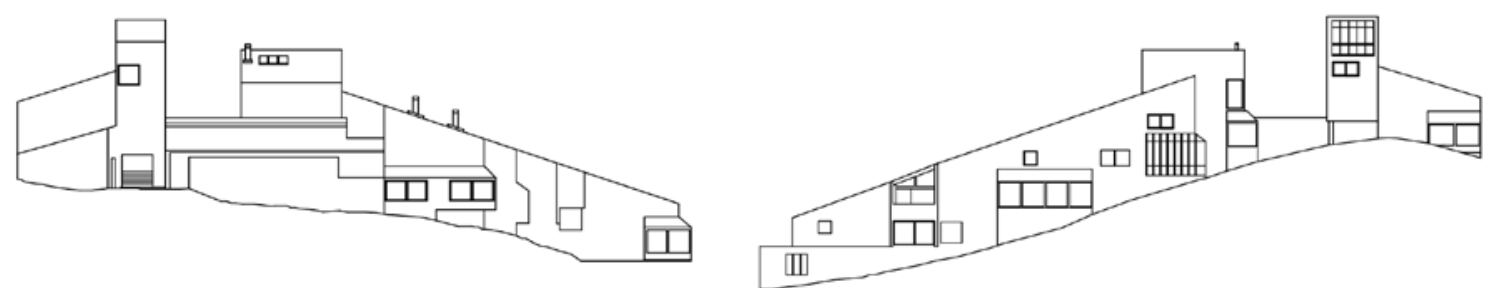

Figures 11 and 12. Reproduction of north (left) and south (right) elevations of Condominium One at Sea Ranch
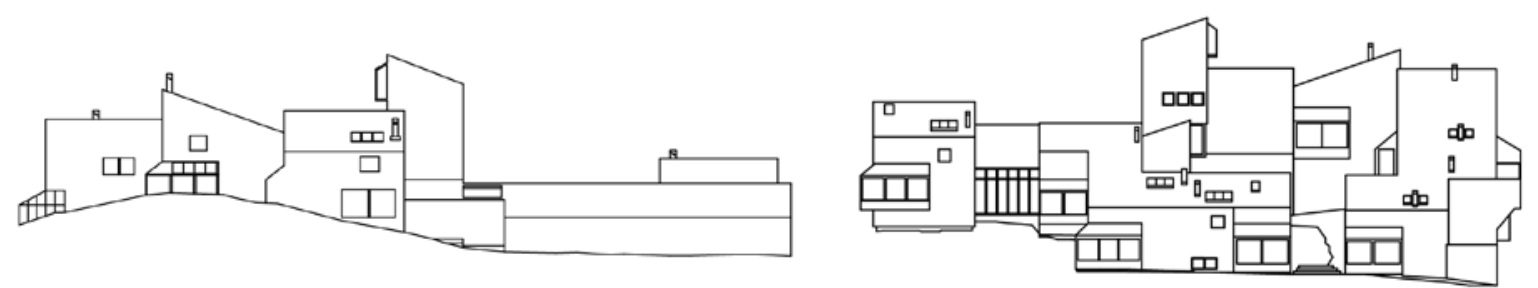

Figures 13 and 14. Reproduction of east (left) and west (right) elevations of Condominium One at Sea Ranch

Analysing the same image of the coastline at Sea Ranch, (see table 2) Bovill's result ( $D=1.329$ ) is higher than the computational result for this paper $(D=1.215)$. This lower result by comparison is typical for the computer program. The results for the remaining images, all produced for this paper, show high percentage differences when comparing the Sea Ranch coastline with the condominium. The first set of results, based on Bovill's original drawings, have a significant difference of $D=0.211$ or $21 \%$. The second set of results, which compares images produced from the original architectural 
documentation, has a smaller range to the first set $(D=0.1325$, or $13 \%)$ however, the results are still not what would be considered "close". It is interesting to note that the fractal dimension of Bovill's image of the coastline ( $D=1.215)$ is close to the fractal dimension of the site plan provided by Lyndon and Alinder $(D=1.249)$, with a $\%_{\text {gap }}$ of $3.4 \%$, this is the tightest range of any two related images studied in this paper.

Table 2: Comparison of average fractal dimensions calculated for Sea Ranch

\begin{tabular}{|l|l|l|l|l|l|l|l|l|}
\hline Results & $\begin{array}{l}D_{\text {(coastline, }} \\
\text { Bovill 96) }\end{array}$ & $\begin{array}{l}D_{\text {(Con.1, }} \\
\text { Bovill 96) }\end{array}$ & $D_{\text {(range) }}$ & $\%_{\text {gap }}$ & $\begin{array}{l}D_{\text {(Coastline, }} \\
\text { Lyndon } \\
\text { Alinder) }\end{array}$ & $\begin{array}{l}D_{\text {(Con.1, original, }} \\
\text { average) }\end{array}$ & $D_{\text {(range) }}$ & $\%_{\text {gap }}$ \\
\hline $\begin{array}{l}\text { Bovill } \\
(1996)\end{array}$ & 1.329 & - & - & - & - & - & - & - \\
\hline $\begin{array}{l}\text { This paper } \\
(2009)\end{array}$ & 1.215 & 1.426 & 0.211 & $21.1 \%$ & 1.249 & 1.382 & 0.1325 & $13.2 \%$ \\
\hline
\end{tabular}

Rather than supporting Bovill's case for a relationship between architecture and its surroundings, the results for Bovill's original images of Sea Ranch suggest a significant difference between the fractal dimensions of the images of the buildings and of their settings. The new results provided in this paper, of an additional elevation and the associated coastline, are marginally more supportive of Bovill's proposition but are still not convincing.

\section{Discussion and Conclusion}

The process of re-testing the results for Amasya and Sea Ranch reveals several weaknesses in various versions of the box-counting method itself. In the first instance, Bovill's original results were produced by hand, using tracing paper and pencil. The number of scales (or grids) he placed over the image were limited for this reason and his results are variable in quality (for Bovill, 28\% is a close result). Lorenz used a more accurate software-based method that relied on a greater number of grids (scales of analysis) but with the same original drawings. Lorenz's research produced a more realistic gap (19\%) but one of the known problems with the box-counting method is that thick lines in the original image can produce anomalous readings; this is why the computational version first reduces all lines to a one-pixel width. These differences or inconsistencies in the method and its application explain the reason why the similarity between the natural and built forms in Amasya can vary between $28 \%$ and $8 \%$ using the same analytical method. 
What does this say about Bovill's conclusion for Amasya; that "the indigenous builders somehow applied the rhythms of nature to their housing site layout and elevation design” (p. 145)? From the point of view of quantifiable data, and with the computational method as a benchmark, the human eye can readily detect visual similarities between objects with a $D$ range of less than $8 \%$. For example, the visual difference between one of Le Corbusier's Modernist elevations, and one of Wright's Prairie House elevations is around 8\% (Ostwald, Vaughan \& Tucker, 2008). This means that the visual similarities between the images of Amasya are not especially striking ( 8\%) and for Sea Ranch even less so ( 13-21\%). In mathematical terms, for comparisons between buildings, a $D$ range of $2 \%$ seems to suggest a high degree of similarity and a $D$ range of over $28 \%$ is a very low degree of similarity.

Ultimately, the results of this paper do not convincingly support Bovill's proposition of a local architecture being a reflection of its natural setting, as the gap in the fractal dimensions of the images analysed is too large to provide compelling evidence. However, these results are limited by the number of images tested, and the selection of images. The images tested in this chapter were chosen to represent Bovill's original data, yet, a more rigorous methodology could be applied and a much larger selection of representational images of the built and natural landscape chosen for analysis. This will be the subject of future research.

\section{Acknowledgement}

This research was supported by an Australian Research Council, Discovery Project grant (ARCDP): DP0770106.

\section{References}

Batty, M. \& Longley, P. (1994). Fractal Cities: A Geometry of Form and Function. New York: Academic Press.

Batty, M. (2005). Cities and Complexity: Understanding Cities with Cellular Automata, Agent-Based Models, and Fractals. Cambridge: MIT Press.

Bechhoefer, W. \& Bovill, C. (1994). Fractal analysis of Traditional Housing in Amasya, Turkey. Changing Methodologies in the field of traditional environment research, Traditional Dwellings and Settlements Working Paper Series, 61, 1-21.

Bechhoefer, W. (1998). Surviving Tourism: Report from Amasya. Preservation of the Vernacular Built Environment in Development Projects Working Paper Series, 114.1-33.

Bechhoefer, W. and Appelby, M. (1997). Fractals, Music and Vernacular Architecture: An Experiment in Contextual Design. Critical Methodologies in the Study of Traditional Environment Working Paper Series, 97, $1-33$.

Ben Hamouche, M. (2009). Can Chaos Theory Explain Complexity in Urban Fabric? Application in Traditional Muslim Settlements. Nexus Network Journal ,11(2), 217-242.

Bovill, C. (1996). Fractal Geometry in Architecture and Design. Boston: Birkhäuser.

Burkle-Elizondo, G. (2001). Fractal Geometry in Mesoamerica. Symmetry: Culture and Science, 12(1-2), 201214.

Burkle-Elizondo, G. \& Valdéz-Cepeda, R.D. (2006). Fractal Analysis of Mesoamerican Pyramids. Nonlinear Dynamics, Psychology, and Life Sciences , 10(1), 105-122. 
Canty, D. (2004). Origins, Evolutions, and Ironies. In D. Lyndon \& J. Alinder (Eds.), The Sea Ranch. New York: Princeton Architectural Press.

Capo, D. (2004). The Fractal Nature of the Architectural Orders. Nexus Network Journal, 6(1), 30-40.

Cardillo, A., Scellato, S., Latora, S. \& Porta. S. (2006). Structural properties of planar graphs of urban street patterns. Physical Review E, 73, 066107-1 - 066107-8.

Cartwright, T. J. (1991). Planning and Chaos Theory. Journal of the American Planning Association. 57(1), 4456.

Feder, J. (1988). Fractals. New York: Plenum Press.

Gozubuyuk, G., Cagdas, G. \& Ediz, O. (2006). Fractal Based Design Model for Different Architectural Languages. In K. Oosterhuis \& L. Feireiss (Eds.), The Architecture Co-Laboratory GameSetandMatch II: on computer games, advanced geometries, and digital technologies. Rotterdam: episode publishers.

Hagerhall, C. M., Purcell, T. \& Taylor, R. (2004). Fractal Dimension of Landscape Silhouette Outlines as a Predictor of Landscape Preference. Journal of Environmental Psychology, 24, 247-55.

Hillier, B. (1996). Space Is the Machine. Cambridge ,UK: Cambridge University Press.

Johnson, E.J. (1986). (Ed.). Charles Moore: Buildings and Projects 1949-1986. New York: Rizzoli.

Joye, Y. (2007). Fractal Architecture Could Be Good for You. Nexus Network Journal. 9 (2), 311-320.

Kakei, H. \& Setsuko, M. (1990). Fractal Analysis of Street Forms. Journal of Architecture, Planning and Environmental Engineering, 8 (414), 103-108.

Keller, J.M., Crownover, R.M. \& Chen, R.Y. (1987). Characteristics of Natural Scenes Related to the Fractal Dimension. IEEE Transactions on Pattern Analysis and Machine Intelligence, PAMI-9(5), 621-627.

Lorenz, W.E. (2003). Fractals and Fractal Architecture. (Masters Dissertation, Department of Computer Aided Planning and Architecture, Vienna University of Technology, 2003).

Lovejoy, S. (1981). Area-Perimeter Relation for Rain and Cloud Areas. Science, New Series, 216, (4542), 185187.

Lung, C.W. \& Zhang, S.Z. (1989). Fractal dimension of the fractured surface of materials. In J. Feder \& A. Aharony (Eds.), Fractals in Physics. Amsterdam: North-Holland.

Lyndon, D. \& Alinder, J. (2004). The Sea Ranch. Princeton Architectural Press: New York

Makhzoumi, J. \& Pungetti, G. (1999). Ecological landscape design and planning: the Mediterranean context. New York: E\&FN Spon.

Mandelbrot, B. (1975). Les Objects Fractals: Form Hasard et Dimension Paris: Flammarion.

Mandelbrot, B. (1982). The fractal Geometry of Nature San Francisco: W.H. Freeman.

Morse, D.R., Lawton, J.H., Dodson, M.M. \& Williamson, M.H. (1985). Fractal dimension of vegetation and the distribution of arthropod body lengths. Nature, 314(6013), 731-733.

Ostwald, M. J. \& Wassell, S.R. (2002). Dynamic Symmetries, Nexus Network Journal, Architecture and Mathematics, 4(1), 123-131.

Ostwald, M. J. \& Vaughan, J. (2008). Determining the Fractal Dimension of the Architecture of Eileen Gray. In N. Gu, F. G. Leman, M. J. Ostwald \& T. Williams (Eds.), Proceedings form ANZASCA 08: Innovation Inspiration and Instruction. Newcastle: ANZSACA.

Ostwald, M.J., Vaughan, J. \& Tucker, C. (2008). Characteristic visual complexity: Fractal dimensions in the architecture of Frank Lloyd Wright and Le Corbusier. In K. Williams (Ed.), Nexus VII: Architecture and Mathematics. Turin: KW Books and Birkhauser. 
Ostwald, M. J. \& Vaughan, J. (2009). Calculating visual complexity in Peter Eisenman's architecture: A computational fractal analysis of five houses (1968-1976). In T. Chang, E. Champion \& S. Chien. (Eds.), Proceedings from CAADRIA 2009: Between Man and Machine Integration/Intuition/Intelligence. Yunlin, Taiwan: National Yunlin University of Science \& Technology Department of Digital Media Design.

Ostwald, M. J. Vaughan, J. \& Chalup, S. K. (2009). A Computational Investigation into the Fractal Dimensions of the Architecture of Kazuyo Sejima. Design Principles and Practices, 3(1), 231 - 244.

Ostwald, M. J. (2009). Fractal Architecture: Knowledge development within and between architecture and the sciences of complexity. Saarbrücken: VDM.

Peebles, P. (1989). The Fractal Galaxy distribution. In J. Feder \& A. Aharony (Eds.), Fractals in Physics. Amsterdam: North-Holland.

Perry, S.G., Reeves, R.W. \& Sim, J.C. (2008). Landscape Design and the Language of nature. Landscape Review, 12(2), 3-18.

Rodin, V. \& Rodina, E. (2000). The Fractal Dimension of Tokyo’s Streets. Fractals. 8(4), 413-418.

Sala, N. (2002). Fractals in Architecture: Some Examples. In G.A. Losa, T.F. Nonnenmacher, D. Merlini \& E.R. Weibel (Eds.), Fractals in Biology and Medicine Volume III. Basel: Birkhäuser.

Spehar, B., Clifford, C.W.G., Newelf, B.R. \& Taylor, R. P. (2003). Universal Aesthetic of Fractals. Computers \& Graphics, 27, 813-820.

Stamps III, A. E. (2002). Fractals, Skylines, Nature and Beauty. Landscape and Urban Planning, 60, $163-184$.

Vaughan, J. \& Ostwald M.J. (2009). Refining the Computational Method for the Evaluation of Visual Complexity in Architectural Images: Significant Lines in the Early Architecture of Le Corbusier. In G. Cagdas \& B. Colakolglue (Eds.), Proceedings from eCAADe27:Computation: The New Realm of Architectural Design. Istanbul: eCAADe.

Voss, R. (1988). Fractals in Nature: From Characterization to Simulation. In H. O. Peitgen \& D. Saupe (Eds.), The Science of Fractal Images. New York: Springer-Verlag. 